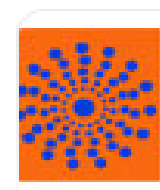

JOURNAL OF BEHAVIOR, HEALTH \& SOCIAL ISSUI

imis

Journal of Behavior, Health \& Social Issues

ISSN: 2007-0780

jcpedro@unam.mx

Asociación Mexicana de Comportamiento y

Salud, A. C.

México

Moral de la Rubia, José; Valle de la O., Adrian

ABOUT THE SUBTLE AND THE MANIFEST IN THE ATLG SCALE

Journal of Behavior, Health \& Social Issues, vol. 5, núm. 2, noviembre-abril, 2013, pp. 103-116

Asociación Mexicana de Comportamiento y Salud, A. C.

Distrito Federal, México

Available in: http://www.redalyc.org/articulo.oa?id=282228907007

How to cite

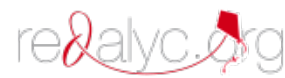

Complete issue

- More information about this article

Journal's homepage in redalyc.org

Scientific Information System Network of Scientific Journals from Latin America, the Caribbean, Spain and Portugal Non-profit academic project, developed under the open access initiative 


\title{
ABOUT THE SUBTLE AND THE MANIFEST IN THE ATLG SCALE
}

\author{
SOBRE LO SUTIL Y MANIFIESTO EN LA ESCALA ATLG
}

\author{
José Moral de la Rubia. \\ Facultad de Psicología. Universidad Autónoma de \\ Nuevo León (UANL), Monterrey, N.L., México. \\ Adrian Valle de la 0. \\ Department of Basic Sciences of Instituto Tecnológico \\ y de Estudios Superiores de Monterrey (ITESM) in \\ Monterrey, Mexico.
}

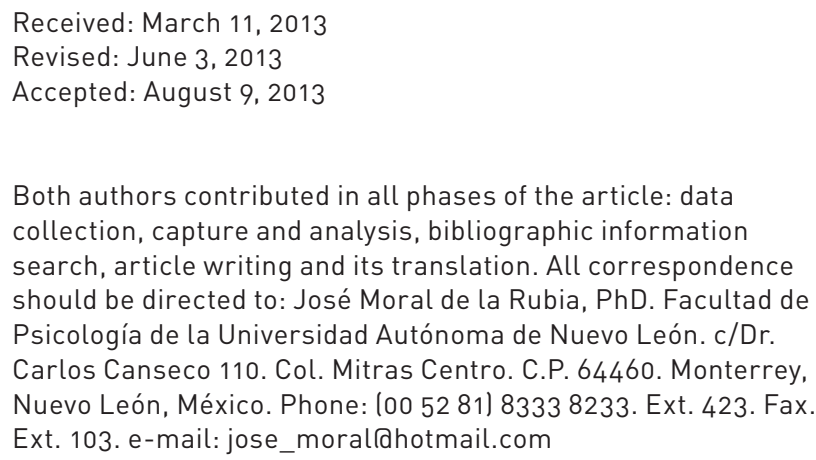

Both authors contributed in all phases of the article: data collection, capture and analysis, bibliographic information search, article writing and its translation. All correspondence should be directed to: José Moral de la Rubia, PhD. Facultad de Psicología de la Universidad Autónoma de Nuevo León. c/Dr. Carlos Canseco 110. Col. Mitras Centro. C.P. 64460. Monterrey, Nuevo León, México. Phone: (00 52 81) 8333 8233. Ext. 423. Fax. Ext. 103. e-mail: jose_moralahotmail.com

Abstract

The aims of this paper were to calculate internal consistency of the Attitude toward Lesbian and Gay Men (ATLG) scale, to determine its factor structure, and to verify the equivalence of the factor structure pattern by gender. An incidental sample of 452 undergraduate students was collected. Internal consistency of its 20 items was high (alpha $=.94)$. It was defined a solution of three factors nested to one general factor: one factor related to an attitude of rejection toward lesbians (ATL), another factor related to an attitude of open rejection toward gay men (ATG-Open), and a third factor related to an attitude of subtle rejection toward gay men (ATG-Subtle). The three factors had high values of internal consistency $(.91, .84$, and .79, respectively). This factor model showed an adequate data fit (Chi-square $/ d f=2.38, \mathrm{RMSEA}=.05, \mathrm{GFI}=.91$, and $\mathrm{AGFI}=.90$ ), and resulted valid for men and women in the multigroup contrast (Chi-square $/ d f=1.80, \mathrm{RMSEA}=.04, \mathrm{GFI}=.87$, and $\mathrm{AGFI}$ $=.83$ ). Nevertheless, the 20 -item ATLG scale could be reduced to the 5 items composing the ATGSubtle factor owing to the extremely strong weights that the general factor had on its three nested factors and the low risk of underestimation of the actual attitudinal rejection that this reduction conveys. It is recommended the use of the ATLG scale with its 20 items in Mexico, and its study in other Spanish-speaking countries.

Key words: Homophobia, attitude, homosexuality, lesbianism, Mexico. 


\section{Resumen}

Los objetivos de este artículo fueron calcular la consistencia interna de la Escala de Actitud hacia Lesbianas y Hombres Homosexuales (ATLG), determinar su estructura factorial y probar la equivalencia del modelo de estructura factorial entre ambos sexos. Se reclutó una muestra incidental de 452 estudiantes universitarios de licenciatura. La consistencia interna de sus 20 ítems fue alta (alfa $=.94)$. Se definió una estructura de tres factores jerarquizados a uno de orden superior: actitud de rechazo hacia lesbianas (ATL), actitud de rechazo abierto hacia hombres homosexuales (ATG-Abierto) y actitud de rechazo sutil hacia hombres homosexuales (ATG-Sutil). Los tres factores tuvieron valores de consistencia interna altos $(.91, .84$ y .79, respectivamente). Este modelo factorial tuvo un ajuste adecuado a los datos (Chi-cuadrado/ $\mathrm{gl}=2.38, \mathrm{RMSEA}=.05, \mathrm{GFI}=.91$ y $\mathrm{AGFI}=.90$ ), y resultó válido para hombres y mujeres en el contraste multigrupo (Chi-cuadrado/gI $=1.80, \mathrm{RMSEA}=.04, \mathrm{GFI}=.87 \mathrm{y} \mathrm{AGFI}=.83$ ). Sin embargo, los 20 ítems de la escala ATLG podrían ser reducidos a los 5 ítems del factor ATG-Sutil por los pesos extremadamente altos que el factor general tuvo sobre sus tres factores anidados y el menor riesgo de subestimar el verdadero rechazo actitudinal que esta reducción conlleva. Se recomienda el uso de la escala ATLG con sus 20 ítems en México y su estudio en otros países de habla hispana.

Palabras clave: Homofobia, actitud, homosexualidad, lesbianismo, México.

\section{Introduction}

The concept of attitude refers to an evaluative positioning of a person before a social object (Haddock, 2004). The term prejudice is defined as a negative attitude, that is to say, a negative evaluation or judgment addressed toward members of a particular social group (Herek, 2006). When there exists a strongly polarized attitude of collective rejection, including very negative attitudes and stereotypes that lead to hostility toward and devaluation of a group of individuals, marginalizing and deeply discrediting them, it is said that there exists stigmatization (Major \& Eccleston, 2005).

Persons with sexual orientation toward same-sex individuals have been stigmatized in western societies since the imposition of Judeo-Christian values (Crompton, 2006). In the past there existed a criminalization of homosexuality in western countries. Nevertheless, nowadays the rejection toward homosexuality has become subtler before an ideology that strongly reinforces a heterosexual hegemony (Neisen, 1990).

This change has occurred within a legal frame of protection and defense of human rights for sexual minority groups (Herek, 2006).
Nowadays, homosexuality is not considered a crime anymore, but the acts of open violence and discrimination toward homosexual personas are an offence. Governmental entities and directives from other organizations have adopted a committed position to enforce the accomplishment of respect to human rights.

In this context of social changes and need for intervention, the evaluation of the attitude toward nonheterosexual persons has become a topic of general interest and thus its evaluation has become increasingly important for social researchers.

Among the evaluation instruments directed to this goal, the Attitudes Toward Lesbians and Gay men (ATLG) scale is one of the most outstanding instruments (Barrientos \& Cárdenas, 2012; Meerendonk, Eisinga, \& Felling, 2003). This scale was created by Herek, (1984).

Herek (1984) started the construction of his scale from a large pool of items. A 2-factor structure was found repeatedly: a 'condemnationtolerance' factor (accounting for 35-45\% of total variance) and a 'beliefs' factor (accounting for $5 \%$ of total variance). The author proposed to take, from the condemnation-acceptation 
factor, the ten most loaded items of attitude toward homosexual men and the ten most loaded items of attitude toward lesbians to create the ATLG scale.

Higher scores on ATLG scale indicate more negative attitudes toward nonheterosexual persons. The ATLG scale and its subscales have repeatedly shown high levels of internal consistency, with Cronbach's alpha coefficients greater than .85 (Herek, 1994).

There exist several confirmatory factor analysis studies about the ATLG scale. Stoever and Morera (2007), after contrasting four models (a model with one factor and three hierarchized models, with 2, 3 and 4 nested factors, respectively), concluded that the hierarchized model constituted by one general factor of sexual prejudice and two nested factors (attitudes toward homosexual men and attitudes toward lesbians) presented the best fitting to the data. Barrientos and Cárdenas (2012) found that a model of 5 factors subordinated to two high-order factors had a better data fit than the Herek's model of two correlated factors, being its fit indexes adequate $(\chi 2 / \mathrm{gl}=3.34$, $\mathrm{CFI}=.93, \mathrm{NFI}=.91, \mathrm{RFI}=.88$ y $\mathrm{RMSEA}=.06)$ by maximum likelihood.

Blackwell and Kiehl (2008) used a linear structural equation modeling and defined the endogenous latent variable 'homophobia' as unidimensional; the model of relations of homophobia to the variables age, race, personal beliefs about the controllability of homosexuality, interpersonal contacts with homosexual persons, and support to a nondiscriminatory policy toward homosexuality showed an adequate data fit (Chi-square/df = 2.30, $\mathrm{RMSEA}=.89, \mathrm{CFI}=.88$, and $\mathrm{TLI}=.86)$. Using confirmatory factor analysis, these last authors had previously found evidence of unidimensionality for the latent variable homophobia, with regression coefficients higher than .70 in 16 out of 20 items composing the ATLG scale.

The factor structure of the ATLG scale is not completely clarified yet. Furthermore, no one of the cited studies has treated it as a unit (20 items) nor has combined exploratory and confirmatory factor analysis to determine its dimensional structure. Thus, the aims of this study were to calculate the internal consistency of the ATLG scale and its factors, to determine the factor structure of the 20 items composing ATLG scale, and to verify the equivalence of the pattern of factor structure between men and women.

It is expected that the model of two correlated factors had the best data fit (Herek, 1984; Meerendonk et al., 2003; Stoever \& Morera, 2007) with a statically equivalent fit between women and men, and high internal consistency for the 20 items (alpha higher or equal than .90) and for both factors (alpha higher or equal .85) (Herek, 1984, 1994).

\section{Method}

\section{Participants}

An incidental sample of 452 health sciences students from a private university in the city of Monterrey, Mexico, was collected. This sample was constituted by 252 women (56\%) and 200 men (44\%). Using binomial test, the number of women resulted significantly higher than the number of men $(p=.02)$. The values of mean, median and mode for age were 19 years old. A high percentage of the sample (84\%) was affiliated to catholic religion (380 out of 452 participants), 5\% (21 out of 452) defined themselves as members of Christian religions, and $11 \%$ (51 out of 452 ) were affiliated to other religions; there were not any atheists among the participants. All of them were single. The sexual orientation was heterosexual in $95.8 \%$ of the participants who answered to this question (432 out of 451), homosexual in $2.2 \%$ (10 out of 451 ), and bisexual in $2 \%$ (9 out of 451 ).

\section{Instruments and materials}

The Attitudes Toward Lesbians and Gay men scale (ATLG; Herek, 1984) is constituted by 20 items, 10 to evaluate the attitudes toward homosexual men (items G1 to 10) and 10 to evaluate the attitudes toward lesbians (items $\mathrm{L} 1$ to $\mathrm{L} 10)$. The items with a redaction related to acceptance of male homosexuality (4 items: G1, G5, G7 and G10) and lesbianism (3 items: L2, L4 and L7) are evaluated along a disagreement, 5-point, Likert-type scale (from 
$1=$ strongly agree to $9=$ strongly disagree). The sum of these items with the remaining 13 negatively-keyed items yields a total score. A higher score means greater rejection (Herek, 1984, 1994). The Spanish-language version of ATLG scale used in this study was created by Cárdenas and Barrientos (2008a).

\section{Procedures}

After getting approval from University authorities and professors, having clearly explained the objectives of this research to the participants, having identified the responsible persons of this study, and having obtained informed consent, the ATLG scale was applied in the classrooms. The answers to the questionnaires were anonymous, and the confidential treatment of individual data was guaranteed. The ethical code from the American Psychological Association (APA, 2002) was followed during the design and implementation of this investigation.

\section{Data analysis}

Exploratory factor analysis (EFA) was performed using the extraction method of Principal Components, and the rotated component matrix was obtained using the Promax method. The method of Generalized Least Squares (GLS) was used to perform confirmatory factor analysis (CFA) because the Mardia's coefficient of multivariate kurtosis was higher than 70 and a lot of items were positively skewed (Rodríguez \& Ruiz, 2008). The different models obtained through EFA and CFA were also contrasted in the samples of men and women, considering each one as an independent sample, in order to verify the invariance of the factor structure by gender. To interpret the data fit, seven indexes were used; their interpretation ranges are shown in the Tables 2 and 3 (Byrne, 2009). The differential data fit between models was contrasted by the chi-square difference test. Internal consistency was estimated using Cronbach's alpha coefficient.
Results

Exploratory factor analysis (subtítulo de segundo orden)

Using Kaiser's criterion, three components accounting for $59.11 \%$ of total variance were defined. In the pattern matrix, the first component enclosed the ten attitudinal items toward lesbianism (ATL) and showed a high internal consistency (alpha $=.91)$. Although item L1 had its highest load in the factor of open rejection toward homosexual men, its second highest load, and greater than .35, was found in the expected factor of rejection toward lesbians. Since its removal did not increase the value of the Cronbach's alpha coefficient, it was considered as a part of the ATL subscale, which is composed of 10 indicators. The second component (ATG-Open) enclosed five items (4 negatively-keyed items: G2, G3, G4 and G6, and 1 positively-keyed item: G10) related to loathing, exclusion, condemnation, obligation to suppress or repress homosexual feelings, and the conceptualization of male homosexuality as a perversion. This second component reflects an open, hostile rejection toward male homosexuality and had a high internal consistency (alpha $=.84)$. The third component (ATG-Subtle) also enclosed five items (3 positively-keyed items: G1, G5 and G7, and 2 negatively-keyed items: G8 and G9) related to the naturalness of male homosexuality, aspects related with marriage and child adoption, and acceptance of a homosexual son. This third component had a high internal consistency (alpha $=.79$ ), and indicates a tendency to a subtle, symbolic rejection toward male homosexuality (Table 1 ). These three components were correlated with moderate values. The attitudinal component toward lesbianism had a correlation of .68 with the component of open rejection toward male homosexuality, and a correlation of .64 with the component of subtle rejection. The correlation between the open-rejection and subtle-rejection components was .56 . 
Table 1.

Pattern matrix

\begin{tabular}{|c|c|c|c|}
\hline \multirow[t]{2}{*}{ Items } & \multicolumn{3}{|c|}{ Components } \\
\hline & 1 & 2 & 3 \\
\hline L5. Female homosexuality is a sin. & .82 & -.18 & .15 \\
\hline $\begin{array}{l}\text { L4. State laws regulating private, consenting lesbian behavior should } \\
\text { be abolished. }\end{array}$ & .80 & .04 & -.29 \\
\hline $\begin{array}{l}\text { L7. Female homosexuality in itself is not problem, unless society } \\
\text { makes it a problem. }\end{array}$ & .74 & .01 & -.05 \\
\hline $\begin{array}{l}\text { L6. The growing number of lesbians indicates a decline in American } \\
\text { morals. }\end{array}$ & .65 & -.13 & .33 \\
\hline $\begin{array}{l}\text { L8. Female homosexuality is a threat to many of our basic social } \\
\text { institutions. }\end{array}$ & .64 & -.07 & .35 \\
\hline $\begin{array}{l}\text { L3. Female homosexuality is bad for society because it breaks down } \\
\text { the natural divisions between the sexes. }\end{array}$ & .55 & .09 & .29 \\
\hline L10. Lesbians are sick. & .54 & .44 & -.15 \\
\hline $\begin{array}{l}\text { L2. A woman's homosexuality should not be a cause for job } \\
\text { discrimination in any situation. }\end{array}$ & .45 & .43 & -.22 \\
\hline L9. Female homosexuality is an inferior form of sexuality. & .40 & .25 & .21 \\
\hline G3. Male homosexuals should not be allowed to teach school. & -.10 & .90 & -.05 \\
\hline G2. I think male homosexuals are disgusting. & -.21 & .89 & .16 \\
\hline G4. Male homosexuality is a perversion. & -.05 & .67 & .28 \\
\hline $\begin{array}{l}\text { G10. Male homosexuality is merely a different kind of lifestyle that } \\
\text { should not be condemned. }\end{array}$ & .10 & .61 & .01 \\
\hline L1. Lesbians just cannot fit into our society. & .49 & .56 & -.20 \\
\hline $\begin{array}{l}\text { G6. If a man has homosexual feelings, he should do. everything he } \\
\text { can to overcome them }\end{array}$ & .35 & .35 & .10 \\
\hline G5. Male homosexuality is a natural expression of sexuality in men. & -.29 & .01 & .89 \\
\hline G8. Sex between two men is just plain wrong. & -.02 & -.02 & .80 \\
\hline $\begin{array}{l}\text { G1. Male homosexual couples should be allowed to adopt } \\
\text { children the same as heterosexual couples. }\end{array}$ & .06 & .05 & .70 \\
\hline G9. The idea of male homosexual marriages seems ridiculous to me. & .23 & .29 & .44 \\
\hline $\begin{array}{l}\text { G7. I would not be too upset if I learned that my son were a } \\
\text { homosexual. }\end{array}$ & .22 & -.02 & .42 \\
\hline Number of items & 10 & 5 & 5 \\
\hline Cronbach's alpha & .91 & .84 & .79 \\
\hline
\end{tabular}

Extraction method: Principal components. Rotation method: Promax. 
The first eigenvalue after extraction was seven times higher than the second one, the internal consistency of the 20 items was very high (alpha $=.94$ ), and, in the unrotated component matrix, all of the items had loads greater than .40. Even one component could be defined by Cattell's criteria; this unique component would account for $47.38 \%$ of total variance. Thus, there were clear indications of unidimensionality.

The factor solution with the 20 items was forced to four components, seeking two components for ATL subscale (open and subtle rejection) and two components for ATG subscale. After extracting the four components and rotating the component matrix, the first component enclosed again the ten items related with attitude toward lesbianism, although item L1 loaded in this factor with its second highest saturation; thus the desired goal was not achieved. When factor analysis was performed separately using only the ten items of ATL subscale, only one component was defined again by Kaiser's criteria, and accounted for $55.13 \%$ of total variance. Therefore, this is a very robust factor. Precisely, its internal consistence was very high (alpha $=.91$ ).

Likewise, the factor solution with the 20 items was forced to two components, seeking one attitudinal component toward lesbianism and another one toward male homosexuality in order to test Herek's original proposal. After extracting the two components and rotating the component matrix, the ten items related to male homosexuality could not be enclosed in only one component, but they overlapped with some attitudinal items toward lesbianism. In the 2-factor solution the first component enclosed eleven items related to open rejection toward homosexuality (L1, L2, L4, L7, L9, L10, G2, G3, G4, G6, and G10), and the second component was related to subtle rejection toward homosexuality (L3, L5, L6, L8, G1, G5, G7, G8, and G9). The correlation between these two components was high $(r$ $=.71$ ), and they accounted for $54.05 \%$ of the total variance. The values of internal consistency of these two components were high $(.90$ and .89, respectively). The first component of open rejection had the highest loads in the attitudinal contents toward lesbianism, which is in agreement with the higher correlation of ATL with ATG-Open than with ATG-Subtle within the 3-component solution.

After separately performing factor analysis using only the ten items related to male homosexuality, two correlated components were defined, which accounted for $59.42 \%$ of the total variance. The first component reflected open rejection (G2, G3, G4, G6, and G10) and the second one reflected subtle rejection $(\mathrm{G} 1$, G5, G7, G8, and G9). The item G9 loaded high in the two factors. The correlation between them was moderate, $r=.59$, and both of them had high values of internal consistencies, as was previously described.

Confirmatory factor analysis in the total sample Four models were contrasted using confirmatory factor analysis: 1) a single-factor model in which the latent variable encloses the twenty items (from G1 to L10), as Blackwell and Kiehl (2008) have proposed. The clear clues of unidimensionality, when using exploratory factor analysis in this sample, support the proposal of a general factor; 2) two correlated factors: attitude toward lesbians with ten indicators (L1 to L10) and attitude toward male homosexuality also with ten indicators (G1 to G10), as Herek (1984, 1994) originally contended. It must be pointed out that the fit indexes totally coincide with a hierarchical model of one general factor of sexual prejudice and two nested factors related to attitude toward lesbians and gay men, as Stoever and Morera (2007) proposed; 3) three correlated factors: attitude toward lesbianism with ten indicators (L1 to L10), attitude of open rejection toward male homosexuality with five indicators (G2, G3, G4, G6 and G10), and attitude of subtle rejection toward male homosexuality with five indicators (G1, G5, G7, G8 and G9), as the exploratory factor analysis solution of this sample suggested; 4 ) four correlated factors: attitude of subtle rejection toward male homosexuality, attitude of open rejection toward male homosexuality, attitude of subtle rejection toward lesbianism (L2, L4, L6, L7 and L8) and attitude of open rejection toward lesbianism (L1, L3, L5, L9 and L10), con- 


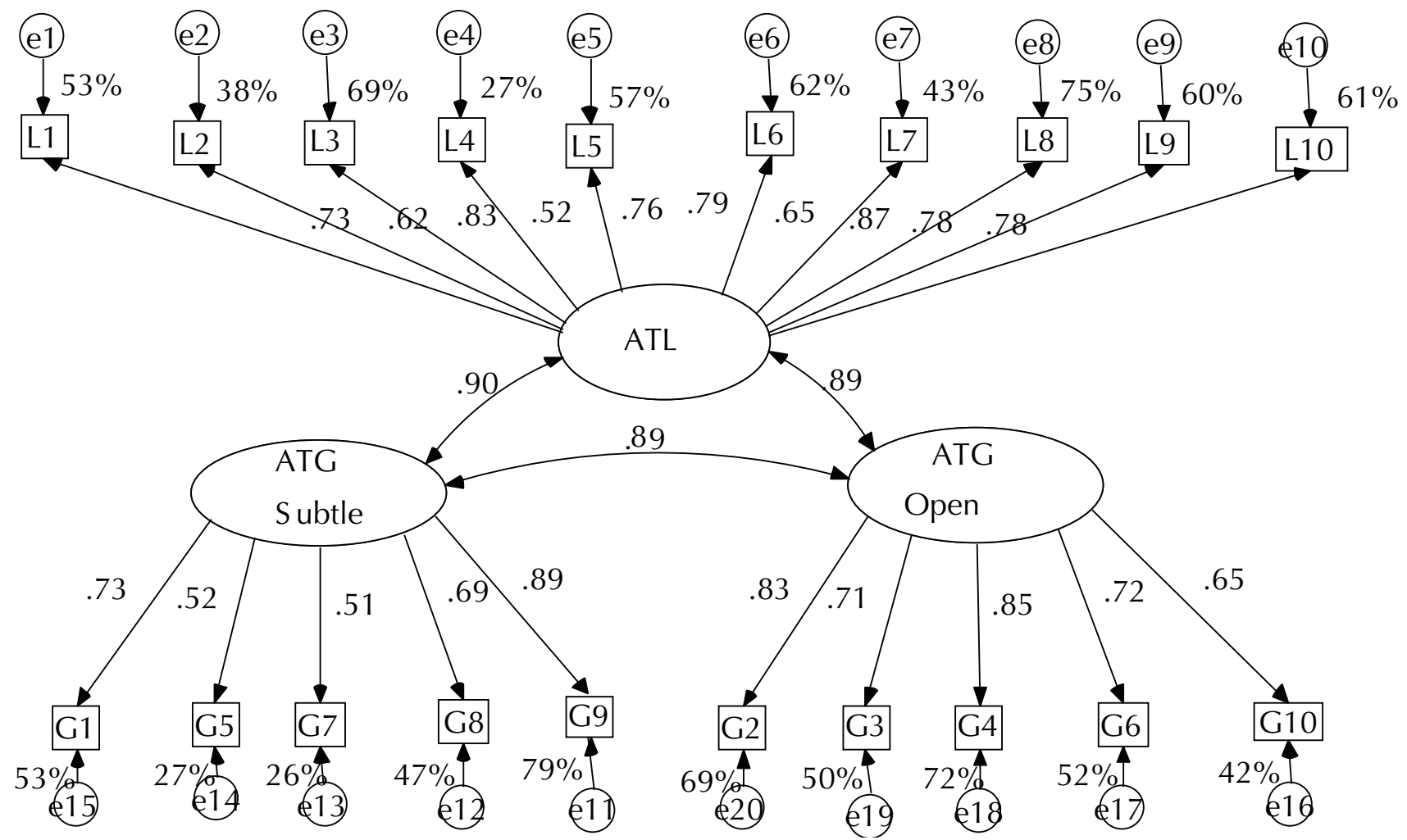

Figure 1. Model of three correlated factors in the total sample.

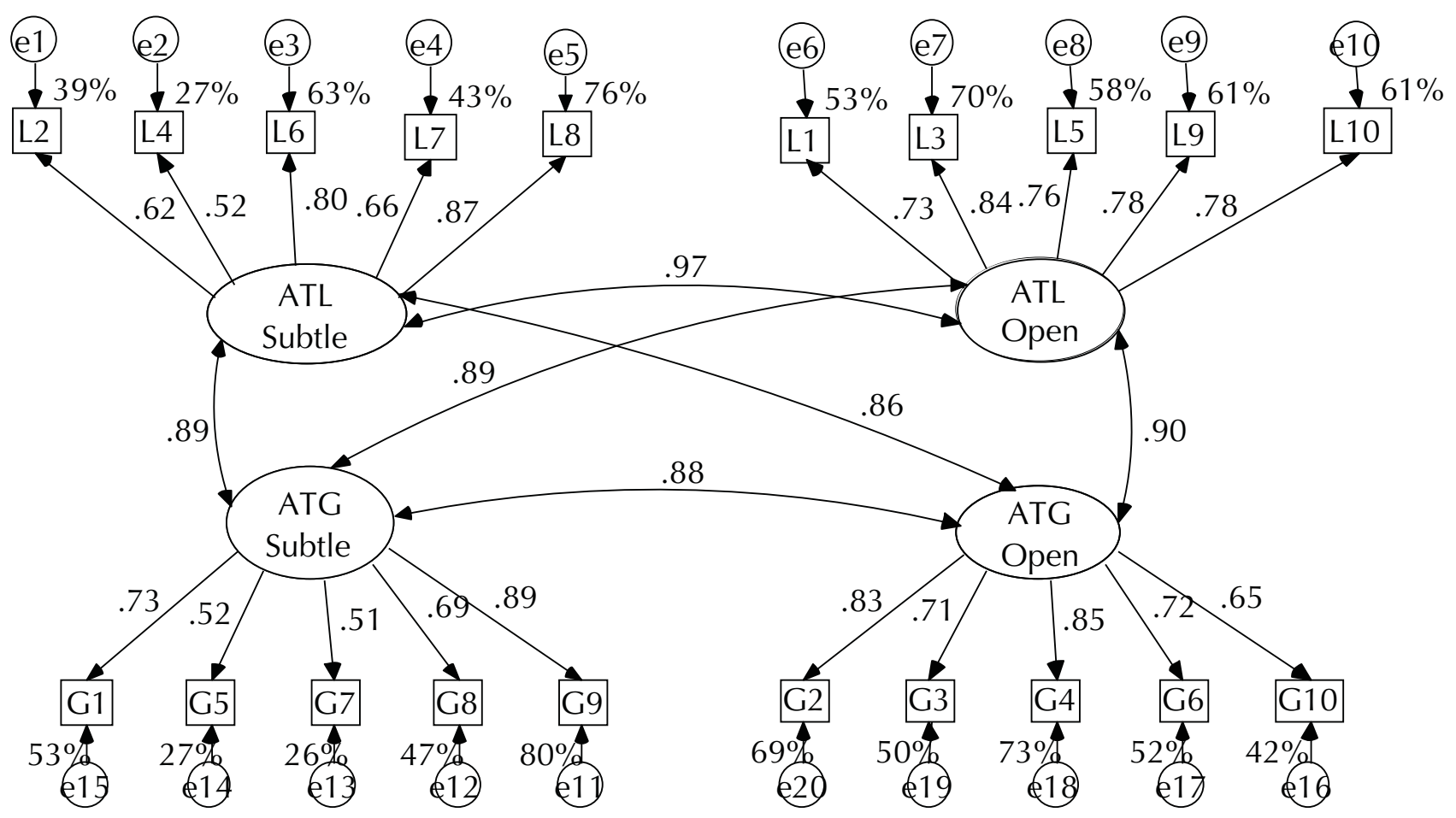

Figure 2. Model of four correlated factors in the total sample. 
trasting the fit of a model grounded on the proposals of modern prejudice (Morrison \& Morrison, 2002; Quiles, Betancor, Rodríguez, Rodríguez, \& Coello, 2003).

The models of three correlated factors (Figure 1) and four correlated factors (Figure 2) yielded the best fit indexes to the data. They showed an adequate data fit (Table 2). The data fit of the two models was statistically equivalent by the Chisquare difference test: dChi-square $(3, \mathrm{~N}=452)$ $=6.71, p=.08$. The model with the worst data fit was the 1-factor model.

Table 2.

Fit indexes in the one-group contrast (total sample)

\begin{tabular}{|c|c|c|c|c|c|c|c|}
\hline \multirow{2}{*}{$\begin{array}{c}\text { Fit } \\
\text { indexes }\end{array}$} & & \multicolumn{3}{|c|}{ Interpretation } & \multicolumn{3}{|c|}{ Models } \\
\hline & & Good & Bad & $1 \mathrm{~F}$ & $2 \mathrm{Fc}$ & $3 \mathrm{Fc}$ & $4 \mathrm{Fc}$ \\
\hline$F D$ & & $\leq 2$ & $\geq 3$ & 1.04 & 0.95 & 0.66 & 0.87 \\
\hline$\chi^{2}$ & & & & 470.15 & 427.23 & 398.34 & 391.63 \\
\hline$d f$ & & & & 170 & 169 & 167 & 164 \\
\hline$p$ & & $>.05$ & $\leq .01$ & $<.01$ & $<.01$ & $<.01$ & $<.01$ \\
\hline$\chi 2 / d f$ & & $\leq 2$ & $\geq 3$ & 2.77 & 2.53 & 2.38 & 2.39 \\
\hline$P N C P$ & & $\leq 1$ & $\geq 2$ & 0.67 & 0.57 & 0.51 & 0.51 \\
\hline \multirow{4}{*}{ RMSEA } & $M$ & $\leq .05$ & $\geq .08$ & .063 & .058 & .055 & .055 \\
\hline & LO & . & & .056 & .051 & .048 & .048 \\
\hline & $\mathrm{HI}$ & & & .069 & .065 & .062 & .063 \\
\hline & $p$ & $>.05$ & & $<.01$ & .025 & .099 & .099 \\
\hline GFI & & $\geq .95$ & $\leq .85$ & .90 & .90 & .91 & .91 \\
\hline AGFI & & $\geq .90$ & $\leq .80$ & .87 & .88 & .90 & .89 \\
\hline
\end{tabular}

Models: 1F: One factor with 20 indicators (G1 to L10); 2Fc: Two correlated factors ('attitude toward lesbians' with 10 indicators [L1 to L10] and 'attitude toward male homosexuality' with 10 indicators [G1 to G10]); 3Fc: Three correlated factors (ATL, or attitude toward lesbianism with 10 indicators [L1 to L10], ATG-open, or attitude of open rejection toward male homosexuality with 5 indicators [G2, G3, G4, G6, and G10] and ATG-subtle, or attitude of subtle rejection toward male homosexuality with 5 indicators [G1, G5, G7, G8, and G9]), 4Fc: 4 correlated factors: Open-L (L1, L3, L5, L9, and L10), SubtleL (L2, L4, L6, L7, and L8), Open-G (G2, G3, G4, G6 and G10) and Subtle-G (G1, G5, G7, G8, and G9).

Confirmatory factor analysis between genders It was tested the data fit of these four unconstrained models between men and women considering them as two independent samples by multigroup contrast. The parameters and indexes were calculated through the method of Generalized Least Squares. 
Using Chi-square difference test, the fit of the model of four correlated factors (4Fc) was statistically equivalent to the model of three correlated factors (3Fc) (dChi-square $=9.83, p=.13)$. The data fit of these two models was differentially better than the data fit of the one-factor and two-factor models (1F-20 and 2F-20). The model of four co- rrelated factors had fit indexes from adequate $(\mathrm{GFI}=.87$ and $\mathrm{AGFI}=.83)$ to good (Chi-square/ $d f=1.81, \mathrm{FD}=1.32, \mathrm{PNCP}=0.59$, and RMSEA $=$ .04 ), and were very close to the fit values for the model of three correlated factors (Chi-square/ $d f=1.80, \mathrm{FD}=1.34, \mathrm{PNCP}=0.60, \mathrm{GFI}=.87, \mathrm{AGFI}$ $=.83$, and RMSEA $=.04)($ Table 3$)$.

Table 3.

Fit indexes in the multi-group contrast (by gender)

\begin{tabular}{|c|c|c|c|c|c|c|}
\hline \multirow{2}{*}{$\begin{array}{c}\text { Fit } \\
\text { indexes }\end{array}$} & \multicolumn{3}{|c|}{ Interpretation } & \multicolumn{3}{|c|}{ Models } \\
\hline & Good & Bad & $1 \mathrm{~F}$ & $2 \mathrm{Fc}$ & $3 \mathrm{Fc}$ & $4 \mathrm{Fc}$ \\
\hline$F D$ & $<2$ & $>3$ & 1.46 & 1.44 & 1.34 & 1.32 \\
\hline$\chi^{2}$ & & & 658.02 & 634.05 & 602.99 & 593.16 \\
\hline$d f$ & & & 340 & 338 & 334 & 328 \\
\hline$p$ & $>.05$ & $<.01$ & $<.01$ & $<.01$ & $<.01$ & $<.01$ \\
\hline$\chi^{2 / d f}$ & $<2$ & $>3$ & 1.93 & 1.88 & 1.80 & 1.81 \\
\hline$P N C P$ & $<1$ & $>2$ & 0.71 & 0.66 & 0.60 & 0.59 \\
\hline RMSEA & $<.05$ & $>.08$ & .046 & .044 & .042 & .042 \\
\hline GFI & $>.95$ & $<.85$ & .85 & .86 & .87 & .87 \\
\hline$A G F I$ & $>.90$ & $<.80$ & .82 & .83 & .83 & .83 \\
\hline
\end{tabular}

See the definitions of four models in the table.

Although the one-factor model showed the worst data fit in the total sample and in the samples divided by gender, there was clear evidence of unidimensionality because the correlations among the factors of the solutions with 2, 3 or 4 dimensions were very high. Considering the exploratory factor analysis solution, and discarding the distinction between subtle and open rejection toward lesbianism owing to the unitary correlation between these two factors $(r=.97)$, finally a model of one general factor with three nested factors was proposed. The fit indexes of this hierarchized model completely coincided with those of the 3 correlated factors model, both in the total sample (Figure 3) and in the samples divided by gender. 


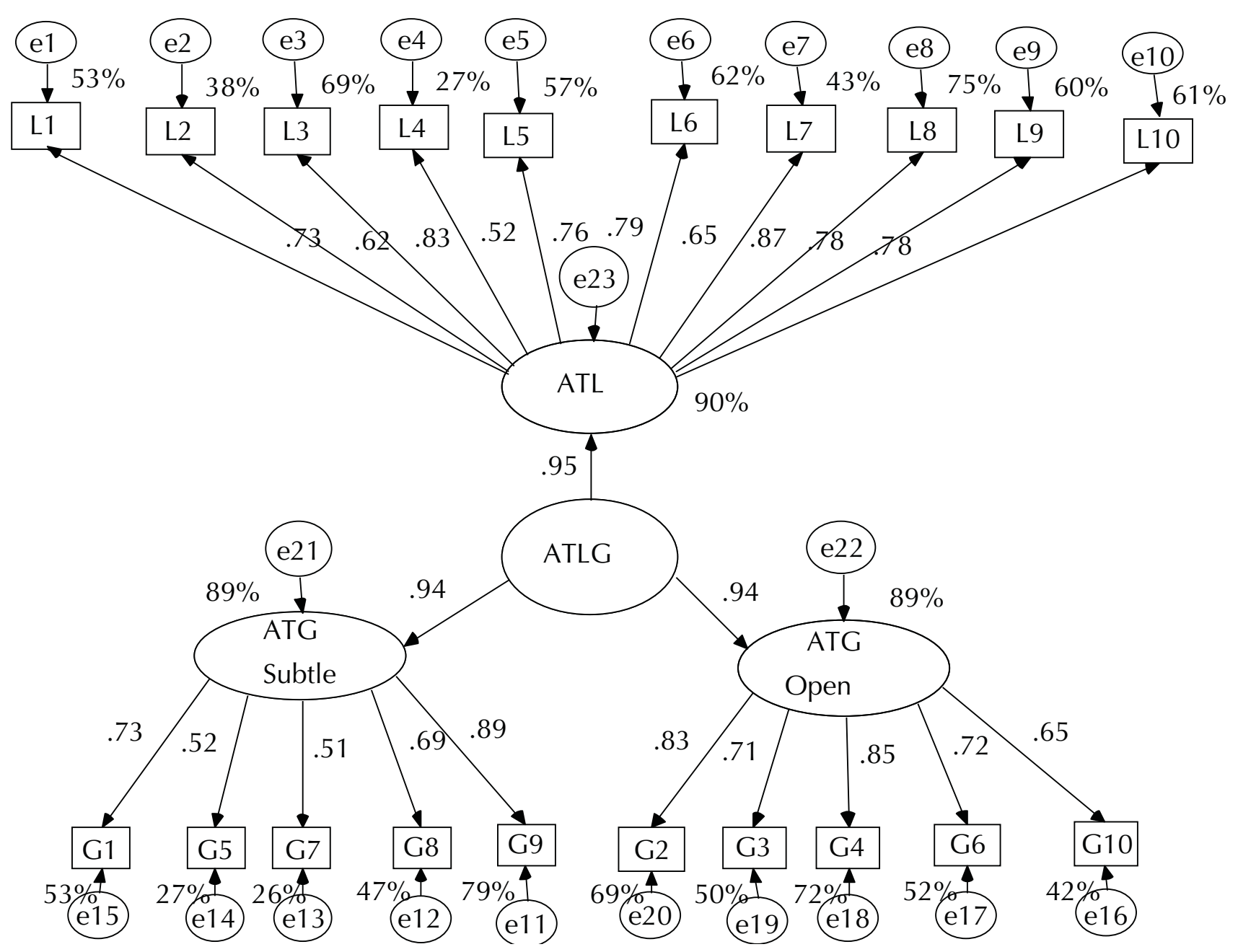

Figure 3. Model of three hierarchized factors in the total sample.

Discussion

The ten items related to lesbianism define clearly a unitary attitudinal factor. This factor could be decomposed in two separate factors, one for an attitude of open rejection and another one for an attitude of subtle rejection (each one enclosing five items), attending to the modern prejudice proposal by Morrison and Morrison (2002). Nonetheless, the correlation between these two factors within the structural model is very close to one, so that when using exploratory factor analysis they merge in only one factor (Kaiser's criteria); hence, this division is artificial. The ten attitudinal items toward male homosexuality, through exploratory factor analysis (Kaiser's criteria), define two factors, one for open rejection and another one for subtle rejection. Nonetheless, in the confirmatory factor analysis, the correlation between these two factors is high.

In the models with 2 and 3 correlated factors, the correlations among the factors are high; thus, the unidimensionality of the 20 items seems clear. However, if the distinction between open and subtle rejection is taken into account, as it is suggested by the present data, it could be proposed a hierarchized model with three factors subordinated to one higher-order factor. This hierarchized model has a better data fit than the models with one and two factors, and is equivalent to the data fit of the model with four 
correlated factors. Nevertheless, this last model seems to be a very forced distinction.

In a Chilean sample, Cárdenas and Barrientos (2008a) found a 3-factor structure in the ATL subscale: traditional values, social sanction, and social rights; and a 2-factor structure for the ATG subscale: stereotyped beliefs and a natural/antinatural dimension. These results differ from the ones presented in this research. Our results are more alike to the solution proposed by Herek (1984), Meerendonk et al. (2003) and the hierarchical model proposed by Stoever and Morera (2007). It must be pointed out that the structure of the present study is in agreement with the current models developed from the works performed by McConahay and Hough (1976), in which it is possible to distinguish one component for open rejection and another one for subtle rejection when measuring racism and prejudice. These new concepts have been already used to measure the attitudes toward homosexuality (Morrison \& Morrison, 2002; Quiles et al., 2003).

At first sight, Herek's scale seems unbalanced, with 7 positively-keyed items and 13 negativelykeyed items, even more when considering the ATL subscale (3 positively-keyed items and 7 negatively-keyed items). Nevertheless, after considering the aspects of open rejection and subtle rejection, the ATLG scale becomes rather equilibrated. It would be possible to argue that the open rejection seems to have more weight in the ATL subscale due to: 1) the very high correlation between its factors of open and subtle rejection (4-factor model), so that they really constitute an only one factor, and 2) the higher correlation between these ten items with the open rejection toward male homosexuality than with subtle rejection toward gay men. This might be the reason that explains why the four-factor solution could not be found through exploratory factor analysis in this sample.

The answers to items enclosed in the factors of symbolic rejection are more heterogeneous (lower values of internal consistency), as this study shows; have higher means (more rejection) and are more discriminant between the attitude toward homosexual men and lesbians, as other studies have found (Morrison \& Morrison, 2002; Quiles et al., 2003); and have lower correlations with scales used to establish convergent validity, as Cárdenas and Barrientos (2008b) observed. By contrast, the answers to the items enclosed in the factors of open rejection are more homogeneous (higher values of internal consistency), have lower means (less rejection), are less discriminant between the attitude toward homosexual men and lesbians, and have higher correlations with scales used to establish convergent validity. Both factors could reflect differential aspects of the attitude. The first one would refer to genuine affirmation of what one feels or thinks without so much weight of the social desirability (traditional or internal attitude), and the second one would refer to modification of what one feels or thinks because of the social pressure before the progressive public and academic acceptance of homosexuality (contemporary or external attitude).

The current academic discursive tendency toward homosexuality is one of acceptation, but the traditional social discourse is one of condemnation, mainly toward male homosexuality (Álvarez, 2002). The implicit aspect is related with the automatically internalized attitude, and this aspect is manifested by disguised and surreptitious social behaviors, as pieces of gossip, jokes, poor labor promotions, and symbolic marginalization in diverse social contexts (tolerated but powerless). The open rejection clearly enters in conflict with the academic attitude, and generates a homogeneously lower condescension. The subtle rejection is quite free of these attitudinal changes in the modern society, and hence it is less monolithic and more condemnatory, reflecting the underlying attitudinal reality.

It is suggested to apply a test to measure social desirability (Moral, García, \& Antona, 2012), and another one to evaluate implicit attitude (Cárdenas \& Barrientos, 2008b) in order to continue studying the nature of this dimensional structure and to contrast this hypothesis. It is predicted that social desirability will have higher correlation with open rejection, and that the implicit attitude will do so with symbolic rejection. Thus the true attitude will be more probably represented by subtle rejection (more unconscious or automatic), and the apparent attitude will do so by open rejection (more conscious or deliberated). 
This study has several limitations: it was performed with a non-probabilistic sample (an incidental sample of health sciences students from a private university in Monterrey, Mexico), thus the conclusions must be applied just as hypothesis to this population and others alike; besides, this investigation used only self-report instruments, so that these results might differ from those obtained from projective tests, reaction time tests or psychophysiological measurements.

In conclusion, the 20 items of the ATLG scale possess a high internal consistency and clear evidences of unidimensionality. Three factors are defined by exploratory factor analysis, one attitudinal factor of rejection toward lesbianism and two factors of rejection toward male homosexuality, one of open rejection and another one of subtle rejection. Owing to the high correlations among these factors, a model of one general factor with three nested factors is proposed. This structure with three hierarchized factors shows a fit to the data from adequate to good, and better than the data fit corresponding to the models with one or two factors. This hierarchized model could be reflecting two differential aspects of the attitude: internal (to affirm what one feels or thinks without so much weight of the social desirability) and external (to modify what one feels or thinks because of the social pressure before the progressive public and academic acceptance of the homosexuality). Furthermore, this structure keeps its invariance between men and women after performing the multigroup contrast. It is hypothesized that social desirability will have higher correlation with open rejection, and that the implicit attitude will do so with symbolic rejection.

It is suggested to continue investigating the properties of ATLG scale in Mexico and its use is recommended because these data maintain the hypothesis of high internal consistency and unidimensionality. Likewise, it is proposed the investigation of this scale in other Spanishspeaking countries, considering the 3-factor model reveled by this study. The ATLG scale seems rather equilibrated in relation to its acceptation-rejection contents when it is taken into account the aspects of overt and covert attitudinal expression.

It should be noted that the open condemnation of homosexuality has fallen sharply (Herek \& McLemore, 2013), especially in the population of university students, but subtle forms of differential treatment and discriminatory qualification still persist and, if not taken into account, they could lead to an underestimation of the actual level of rejection (Cárdenas, 2007). The importance of the balance between open and subtle rejection aspects found in the ATLG scale remarks its usefulness for assessing sexual prejudice.

Owing to the extremely strong weights that the general factor has on its three nested factors it could be proposed that the 20 -item ATLG scale were simplified to the form of the 10-item ATL subscale, the 5-item ATG-Open subscale or the 5-item ATG-Subtle subscale. Considering the former suggestion, the attempt of reducing the ATLG scale to the 5 items composing the factor of open rejection toward gay men or to the 10 items of attitude toward lesbians could incur in the dreaded underestimation. In any case, the reduction to the 5 items composing the factor of subtle rejection toward gay men could lead to a better estimate. Probably the best way to apply the scale is with its 20 items because they combine aspects of subtle and open rejection.

\section{References}

Álvarez, J. L. (2002). Homosexualidad: Derrumbe de mitos y falacias [Homosexuality: Colapse of myths and fallacies]. México: Benemérita Universidad de Puebla.

American Psychological Association (2002). Ethical principles of psychologists and code of conduct. American Psychologist, 57, 10601073, available via: http://dx.doi:10.1037/0003066X.57.12.1060

Barrientos, J. \& Cárdenas, M. (2012). A confirmatory factor analysis of the Spanish language version of the Attitudes Toward Lesbians and Gay Men Scale (ATLG). Universitas Psychologica, 11, 579-586.

Blackwell, C. W. \& Kiehl, E. M. (2008). Homophobia in registered nurses: Impact on LGB youth. 
Journal of LGBT Youth, 5(4), 28-44, available via: http://dx.doi:10.1080/19361650802222989

Byrne, B. (2009). Structural equating modelling with AMOS: Basic concepts, applications, and programming (2nd ed.). New York, NY: Taylor \& Francis Group.

Cárdenas, M. (2007). Escala de racismo moderno: propiedades psicométricas y su relación con variables psicosociales [The modern racism scale: Psychometric properties and its relationship with psychosocial variable]. Universitas Psychologica, 6, 255-262.

Cárdenas, M. \& Barrientos, J. (2008a). The Attitudes Toward Lesbians and Gay Men Scale (ATLG): Adaptation and testing the reliability and validity in Chile. Journal of Sex Research, 45(2), 140-149, available via: http://dx.d oi:10.1080/00224490801987424

Cárdenas, M. \& Barrientos, J. (2008b). Actitudes explícitas e implícitas hacia los hombres homosexuales en una muestra de estudiantes universitarios en Chile [Explicit and Implicit Attitudes toward Gay Men in a University Sample in Chile]. Psykhe, 17(2), 17-25, available via: http://dx.doi:10.4067/S071822282008000200002

Crompton, L. (2006). Homosexuality and civilization. Cambridge: Belknap.

Haddock, G. (2004). Contemporary perspectives on the psychology of attitudes. New York: Publisher Taylor \& Francis.

Herek, G. M. (1984). Attitudes toward lesbians and gay men: A factor analytic study. Journal of Homosexuality, 10(1/2), 39-51, available via: http://dx.doi:10.1300/J082v10n01_03

Herek, G. M. (1994). Assessing heterosexuals' attitudes toward lesbians and gay men: A review of empirical research with the ATLG scale. In B. Greene \& G.M. Herek (Eds.), Lesbian and gay psychology: Theory, research, and clinical applications (pp. 206-228). Thousand Oaks, CA: Sage Publications.

Herek, G. M. (2006). Legal recognition of same sex relationship in the United State: A social sciences perspective. American Psychologist, 61(6), 607-621, available via: http://dx.doi. org/10.1037/0003-066X.61.6.607

Herek, G.M., \& McLemore, K. A. (2013). Sexual prejudice. Annual Review of Psychology,
64, 309-333, available via: http://dx.doi. org/10.1146/annurev-psych-113011-143826

Major, B., \& Eccleston, C. P. (2005). Stigma and social exclusion. En D. Abrams, J. Marques \& M. A. Hogg (Eds.), Social psychology of inclusion and exclusion (pp. 63-87). New York: Psychol. Press.

McConahay, J. B. \& Hough, J. C. (1976). Symbolic racism. Journal of Social Issues, 32(2), 23-45, available via: doi:10.1111/j.1540-4560.1976. tb02493.x

Meerendonk, B., Eisinga, R. \& Felling, A. (2003). Application of Herek's attitudes toward lesbians and gay men scale in the Netherlands. Psychological Reports, 93(1), 265-275, available via: http://dx.doi:10.2466/PR0.93.5.265-275

Moral, J., García, C. H. y Antona, C. J. (2012). Traducción y validación del Inventario Balanceado de Deseabilidad Social al Responder en una muestra probabilística de estudiantes universitarios mexicanos [Translation and validation of the Balanced Inventory of Desirable Responding in a probability sample of Mexican university students]. Revista de Psicología GEPU, 3(2), 2032.

Morrison, M. \& Morrison, T. (2002). Development and validation of a scale measuring modern prejudice toward gay men and lesbian women. Journal of Homosexuality, 43(2), 15-37, available via: http://dx.doi:10.1300/J082v43n02_02

Neisen, J. H. (1990). Heterosexism: redefining homophobia for the 1990s. Journal of Gay and Lesbian Mental Health, 1(3), 21-35, available via: http://dx.doi.org/10.1080/19359705.1990. 9962143

Quiles, M. N., Betancor, V., Rodríguez, R., Rodríguez, A. \& Coello, E. (2003). La medida de la homofobia manifiesta y sutil [The assessment of overt and subtle homophobia]. Psicothema, 15, 197-204.

Rodríguez, M. N. \& Ruiz, M. A. (2008). Atenuación de la asimetría y de la curtosis de las puntuaciones observadas mediante transformaciones de variables: Incidencia sobre la estructura factorial [The Reduction of skewness and kurtosis of observed variables by data transformation: Effect on factor structure]. Psicológica, 29, 205-227. 
Stoever, C. J. \& Morera, O. F. (2007). A confirmatory factor analysis of the Attitudes Toward Lesbians and Gay Men (ATLG) measure. Journal of Homosexuality, 52(3-4), 189-209, available via: http://dx.doi:10.1300/J082v52n03_09

Self-references for authors: 1

Self-references for the JBHSI: 0 